\title{
Health effects of ethanolic extract from seeds of lady finger
}

\author{
Jasadee Kaewsrichan $^{1}{ }^{\mathbb{D}}$, Paweena Wongwitwichot ${ }^{1} \mathbb{D}$, Sirikhwan Manee $^{2} \mathbb{D}$
}

Cite this article as:

Kaewsrichan, J., Wongwitwichot, P., Manee, S. (2020). Health effects of ethanolic extract from seeds of lady finger. Food and Health, 6(2), 90-97. https://doi.org/10.3153/FH200010

\section{${ }^{1}$ Prince of Songkla University,Faculty of Pharmaceutical Sciences and Drug Delivery System Excellence Center, Department of Pharmaceutical Chemistry, Hat-Yai, Songkhla 90112, Thailand \\ 2 Prince of Songkla University, Faculty of Traditional Thai Medicine, Hat-Yai, Songkhla 90112, Thailand}

\section{ORCID IDs of the authors:}

J.K. 0000-0003-4316-3814

P.W. 0000-0002-5112-0913

S.M. 0000-0003-2958-4284

Submitted: 25.09 .2019

Revision requested: 10.11 .2019

Last revision received: 19.11 .2019

Accepted: 22.11 .2019

Published online: 10.02 .2020

Correspondence: Jasadee KAEWSRICHAN

E-mail: jasadee.k@psu.ac.th

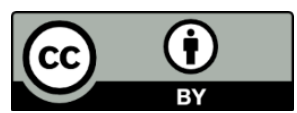

(C) Copyright 2020 by ScientificWebJournals Available online at

http://jfhs.scientificwebjournals.com

\begin{abstract}
Health benefits of lady finger were explored in this study by which the ethanol extract from the seeds was utilized for testing. In high glucose $(350 \mathrm{mmole} / \mathrm{L})$ medium, the proliferative activity of $\mathrm{C} 2 \mathrm{C} 12$ cells was inferior, but their viability was improved following treated with the extract. The activities of antioxidant enzymes, superoxide dismutase (SOD) and catalase (CAT), were also enhanced. In response to such high glucose concentration, glucose uptake ability of these cells was compromised. The extract was demonstrated to increase the ability of glucose uptake by approximately equal to the effect of $200 \mathrm{nmole} / \mathrm{L}$ insulin. High intracellular reactive oxygen species (ROS) of RBM-MCS cells grown in high glucose containing medium was elicited. The level of ROS was reduced when the cells were cultured in contact with the extract. L929 cells were made inflammation and oxidative stress by incubating with $37.5 \mu \mathrm{mole} / \mathrm{L} \mathrm{DPPH}$ for $30 \mathrm{~min}$. The release of tumor necrosis factor- $\alpha$ (TNF- $\alpha$ ) and interleukin 6 (IL-6) from these inflamed cells was inhibited by such treatment. Thus, lady finger might be advantageous in the protection of cells in the body that would be damaged or being susceptible to hyperglycemia and diabetes.
\end{abstract}

Keywords: Lady finger, Polyphenols, Healthy diet, Nutrient, Obesity, Chronic inflammation, Metabolic disease 


\section{Introduction}

Consumption of healthy diets throughout the life-course helps prevent malnutrition and a range of non-communicable diseases (NCDs), such as obesity, diabetes, heart disease, stroke, and cancer. Rapid urbanization changes lifestyles and shift dietary patterns. Having more foods high in energy, fats, free sugars, salt, and sodium, but insufficient of fruit, vegetables, and whole grains, are major epidemic factors of NCDs ("Healthy diet," 2018). A healthy dietary set can be varied depending on individuals and is influenced by both social and economic factors. Indeed, the basic principle of what constitutes a healthy diet is the same and requires a variety of different foods, since no single food contains all the essential nutrients the body needs to stay healthy and work properly ("A healthy, balanced diet," 2016). A healthy diet will provide the right amount of energy to maintain energy balance, which is where the calories taken in from the diet are equal to the calories used by the body. For adults, total fat should not exceed $30 \%$ of total energy intake with saturated fats of less than $10 \%$ and trans-fats of less than $1 \%$, less than $10 \%$ of free sugars, less than $5 \mathrm{~g}$ per day of salt, and at least five portions of fruit and vegetables per day ("Healthy diet," 2018). Excess calories intake is stored as fat, and obesity is the consequence due to chronic energy imbalance. An association between an unhealthy lifestyle and obesity has been obvious. Obesity changes the body physiological responses through cytokines and pro-inflammatory factors produced by adipocytes, which involve low-grade inflammation. When continuously existing, the inflammation becomes chronic and influences other systems by altering their functions to cause different degenerative diseases (Castro et al., 2017). Therefore, nutritional approach is implicated as an effective tool to manage obesity and obese-associated indisposition. In this study, lady finger, which is a plant with the scientific name Abelmoschus esculentus (L.) Moench of the family Malvaceae was chosen for evaluation of health beneficial effects. The selection criteria were that the plant is naturalized in the world's tropical and subtropical areas and its edible fruits are popular for consumption. The fruits are rich in vitamins A, C, and K, polyphenols, protein, and fiber. Accordingly, serious diseases such as cancers, diabetes, chronic inflammation, as well as heart and brain malfunction are expected to improve when the fruits of lady finger are regularly consumed (Ware, 2019). In this work, seeds of lady finger were extracted by using ethanol and examined for optimistic activities, including anti-oxidation, anti-inflammation, inductive proliferation, and beneficial properties of increasing glucose uptake and utilization by muscle cells. Results may assist the daily consumption of lady finger for proper health and prevention/delay the onset of NCDs.

\section{Materials and Methods}

\section{Materials}

Cell lines of L929 mouse fibroblast (CRL-6364 $\left.{ }^{\mathrm{TM}}\right)$, PC12 rat adrenal gland (CRL-1721 ${ }^{\mathrm{TM}}$ ), and $\mathrm{C} 2 \mathrm{C} 12$ mouse myoblast $\left(\mathrm{CRL}-1772^{\mathrm{TM}}\right)$ were bought from American Type Culture Collection-Cell lines (ATCC). RBM-MSCs (rat bone marrow derived mesenchymal stem cells) were kindly obtained from authors of the previous study (Wongwitwichot and Kaewsrichan, 2017). RPMI 1640 medium, Dulbecco's modified eagle's medium (DMEM), fetal bovine serum (FBS), penicillin/streptomycin, Dulbecco's phosphate buffered saline (DPBS) and trypsin ethylenediamine tetraacetic acid (EDTA) were purchased from Gibco $^{\mathrm{TM}}$. APO-BrdU ${ }^{\mathrm{TM}}$ TUNEL Assay Kit was obtained from Molecular Probes, Inc. Superoxide Dismutase Activity Assay Kit (Colorimetric) was from Abcam $^{\circledR}$. Catalase Activity Colorimetric/Fluorometric Assay Kit was acquired from BioVision, Inc. Mouse TNF-alpha Quantikine ELISA Kit and Mouse IL-6 Quantikine ELISA Kit were purchased from R\&D System (MN, USA). Tetrazolium salt 3-(4,5-dimethylthiazol-2-yl)-2,5-diphenyltetrazolium bromide (MTT) was from Hi Media Labs (Mumbai, India). 2-( $N$-(7-Nitrobenz-2-oxa-1,3-diazol-4-yl)Amino)-2Deoxyglucose, (2-NBDG), was bought from Thermo Fisher Scientific (MA, USA). Folin-Ciocalteu reagent, gallic acid, ascorbic acid, sodium acetate, 2,2-diphenyl-1-picrylhydrazyl (DPPH), 2',7'-dichlorodihydrofluorescein diacetate (DCFHDA), 2,4,6-tripyridyl-striazine (TPTZ), $\mathrm{FeCl}_{3}$, L-dopa, and mushroom tyrosinase were acquired from Sigma Aldrich (Darmstadt, Germany). Absolute ethanol was purchased from Loba Chemie (Mumbai, India). Other chemicals were of analytical grade and bought from Merck (NJ, USA).

\section{Seed Extract Preparation}

Fruits of lady finger were bought from a farm in Nakhonpathom province, Thailand. Seeds of the fruit were collected and completely dried in a hot-air oven at $60^{\circ} \mathrm{C}$. Ethanol was used as a solvent for extraction of dried seeds using a solid: liquid ratio of 1:2. The seed sample was soaked in ethanol overnight at room temperature in close container with regularly shaking. The extract was filtered through a bruckner funnel and concentrated on a water bath at $60^{\circ} \mathrm{C}$ for $2 \mathrm{~h}$. The extracted residue was reconstituted in ethanol and stored at $4^{\circ} \mathrm{C}$ until analysis.

\section{Cell Culture}

The cell lines of L929 and C2C12 and RBM-MSCs were routinely grown in DMEM medium, whereas RPMI 1640 was used for growing PC12 cells. To prepare a complete medium, 
each medium was supplemented with $10 \%$ fetal bovine serum, $100 \mathrm{U} / \mathrm{mL}$ penicillin, and $100 \mu \mathrm{g} / \mathrm{mL}$ streptomycin. The cells were routinely cultured in a $5 \% \mathrm{CO}_{2}$ incubator at $37^{\circ} \mathrm{C}$ and sub-cultured every 3 days.

\section{Cytotoxic Test}

The extract was tested for cytotoxicity by using MTT assay. Briefly, cells of $80 \%$ confluence were incubated with varying concentrations of a sample for $24 \mathrm{~h}$. The supernatant was withdrawn and replaced by excess MTT reagent $(5 \mathrm{mg} / \mathrm{mL}$ in PBS). The cells were continually incubated for $4 \mathrm{~h}$ at $37^{\circ} \mathrm{C}$ in the dark before the reagent was removed. DMSO of $150 \mu \mathrm{L}$ was then added to each well for dissolving the formazan product, and the $\mathrm{OD}_{570}$ was measured by using a microplate reader (SPECTROstar Nano, BMG LABTECH, Germany).

\section{Total Phenolic Content (TPC) and Antioxidant Activity}

The Folin-Ciocalteu method was used for determination of TPC (Azlim Almey et al., 2010). Briefly, fifty micro litter of sample was added in a tube containing $375 \mu \mathrm{L}$ of ten-fold diluted Folin-Ciocalteu reagent. After thoroughly mixed for $5 \mathrm{~min}, 375 \mu \mathrm{L}$ of $6 \% \mathrm{w} / \mathrm{v}$ sodium carbonate solution was added, mixed, and incubated at room temperature for $90 \mathrm{~min}$. Then, the $\mathrm{OD}_{725}$ was measured by using a microplate reader. Gallic acid was a standard. Its calibration curve was constructed by using a concentration range of $0.01-0.10 \mathrm{mg} / \mathrm{mL}$. Data were calculated and expressed as $\mathrm{mg} / \mathrm{mL}$ gallic acid equivalent.

Antioxidant activity of the extract was determined by two methods, e.g., DPPH and FRAP (Ferric Reducing Antioxidant Power), respectively. For DPPH assay, the method of Alama et al. was performed with some modifications (Alam et al., 2017). In brief, forty micro litter of sample was added to $160 \mu \mathrm{L}$ of $0.1 \mu$ mole/L DPPH (2,2-diphenyl-1-picrylhydrazyl) solution in a well of 96-wells plate and incubated in the dark at room temperature for $30 \mathrm{~min}$. Then, the OD515 was measured using a microplate reader. A calibration curve of trolox at concentrations ranging between 0 and 500 $\mu$ mole/L was plotted. Data were expressed as $\mu$ mole/L trolox equivalent. In analysis of FRAP activity (Rehakova et al., 2014), three solutions were prepared, e.g., $300 \mathrm{mmole} / \mathrm{L}$ acetate buffer $\mathrm{pH} 3.6 ; 10 \mathrm{mmole} / \mathrm{L}$ of TPTZ in $40 \mathrm{mmole} / \mathrm{L} \mathrm{HCl}$; and $20 \mathrm{mmole} / \mathrm{L}$ of $\mathrm{FeCl} 3$. FRAP reagent was freshly prepared by mixing $25 \mathrm{~mL}$ of acetate buffer, $2.5 \mathrm{~mL}$ of TPTZ solution and $2.5 \mathrm{~mL}$ of $\mathrm{FeCl}_{3}$. The FRAP reagent of $750 \mu \mathrm{L}$ and a sample of $25 \mu \mathrm{L}$ were mixed and incubated in the dark for $10 \mathrm{~min}$. After that the OD593 was measured using a microplate reader. In compared to known concentration of $\mathrm{FeCl}_{2}$, results were calculated and expressed as $\mu \mathrm{mole} / \mathrm{mL}$ $\mathrm{Fe}^{2+}$ equivalent.

\section{Proliferation Assay}

Cells of $5 \times 10^{4}$ cells $/ \mathrm{mL}$ in complete medium were seeded in a 6-wells plate and cultured to nearly $100 \%$ confluent in a $5 \%$ $\mathrm{CO}_{2}$ incubator at $37^{\circ} \mathrm{C}$. Then, the growing cells were starved overnight in serum-free medium, and incubated in medium supplemented with $37.5 \mu \mathrm{mole} / \mathrm{L}$ DPPH for $30 \mathrm{~min}$ by which cellular oxidative stress was established. A linear scratch was created on a well by using a sterile pipette tip. Any debris was removed by gentle washing with phosphate buffer saline (PBS) solution, followed by incubation in medium supplemented with the extract for 2 days. Photography was carried out on each day and the image J software was used for measuring the scratch distance closure. The percentage (\%) of distance closure was calculated by using an equation below.

$\%$ Distance closure $=$

Distance of the scratch on day 0 - Distance of the scratch on day 1 or 2 Distance of the scratch on day 0

\section{Apoptotic Activity Assay}

The terminal deoxynucleotidyl transferase (TdT) dUTP nickend labelling (TUNEL) assay was utilized for detection of apoptotic cells as induced by test compounds by using APOBrdU ${ }^{\mathrm{TM}}$ TUNEL Assay Kit according to the manufacturer's recommendations. Cells of $60-70 \%$ confluence were challenged with $350 \mathrm{mmole} / \mathrm{L}$ glucose with or without the addition of the extract for $72 \mathrm{~h}$. After that the cells were collected and apoptotic determination was performed by using flow cytometer (CytoFLEX S, Beckman Coulter, CA, USA).

\section{Activity of Antioxidant Enzymes}

The previously challenged cells were collected by centrifugation (1500xg, $15 \mathrm{~min}$ ), and lysed by sonication in a specified buffer. The supernatant was collected by centrifugation at $12000 \mathrm{xg}$ at $4^{\circ} \mathrm{C}$ for $10 \mathrm{~min}$ and measured for enzyme activity. Controls were cells grown in serum free medium without any challenges.

\section{Superoxide dismutase (SOD) activity}

SOD activity was determined by using Superoxide Dismutase Activity Assay Kit. Results were calculated by comparing with that of controls and represented as fold increase.

\section{Catalase (CAT) activity}

CAT activity was measured using Catalase Activity Colorimetric/ Fluorometric Assay Kit. The enzyme activity was reported as $\mathrm{mU} / \mathrm{mL}$. One unit of catalase is the amount of CAT able to decompose $1.0 \mu$ mole of $\mathrm{H}_{2} \mathrm{O}_{2}$ per min at $\mathrm{pH} 4.5$ at $25^{\circ} \mathrm{C}$. 
Tumor Necrosis Factor- $\alpha(T N F-\alpha)$ and Interleukin 6 (IL-6) Inhibition

The activities of TNF- $\alpha$ and IL- 6 in culture supernatant were determined based on ELISA technique. Briefly, a monoclonal antibody specific for either mouse TNF- $\alpha$ or mouse IL- 6 was pre-coated onto a microplate. Standards, control, and samples were separately pipetted into the wells, and either TNF- $\alpha$ or IL- 6 present was bound by the immobilized antibody. After washing away any unbound substances, an enzyme-linked polyclonal antibody specific for mouse TNF- $\alpha$ or IL-6 was added to the wells. Following a wash to remove any unbound antibody-enzyme reagent, a substrate solution was added to the wells. The enzyme reaction yielded a blue product that turns yellow when the Stop Solution was added. The intensity of the formed colour was proportional to the amount of TNF$\alpha$ or IL- 6 bound in the initial step. The sample values were read off by comparing to the standard curve, calculated, and reported as the percentage (\%) of inhibition.

\section{Glucose Uptake}

$\mathrm{C} 2 \mathrm{C} 12$ cells were determined for glucose uptake activity. The cells of $80 \%$ confluence were starved in serum free medium for $24 \mathrm{~h}$ and incubated with the extract for $24 \mathrm{~h}$. A fluorescent glucose analogue, 2-NBDG, was inoculated into culture medium to a final concentration of $180 \mu \mathrm{mole} / \mathrm{L}$, which was used to replace the old medium. The treated cells were incubated in a $\mathrm{CO}_{2}$ incubator for $30 \mathrm{~min}$ following such replacement, collected by centrifugation (1500xg, $15 \mathrm{~min})$, and subjected to flow cytometric analysis. Control cells were incubated in medium supplemented with $200 \mathrm{nmole} / \mathrm{L}$ insulin for $30 \mathrm{~min}$ before the addition of the fluorescent dye.

\section{Intracellular Reactive Oxygen Species (ROS)}

RBM-MSCs were cultured in medium supplemented with the extract for $24 \mathrm{~h}$ before the old medium was replaced by a new medium that contained $10 \mu$ mole/L DCFH-DA. These cells were incubated further for $1 \mathrm{~h}$, washed with PBS, incubated in medium supplemented with $150 \mu$ mole $/ \mathrm{L} \mathrm{H}_{2} \mathrm{O}_{2}$ for $4 \mathrm{~h}$, and then observed under a fluorescence microscope (OLYMPUS BX61).

\section{Statistical Analysis}

All experiments were done in triplicate. Data were presented as mean \pm standard deviation (S.D.). One-way ANOVA was used, and $p<0.05$ was considered significant of the results.

\section{Results and Discussion}

Previously, the extract from seeds of lady finger was demonstrated to contain polyphenols, tannin, flavonoids, terpenoids, saponins, long chain fatty acids, and glutathione (Manee and Kaewsrichan, 2017). In the present work, data of TPC, and antioxidant activity regarding DPPH and FRAP assays were additionally reported. The TPC was equivalent to $9.2 \mathrm{mg}$ gallic acid $/ \mathrm{mL}$. The DPPH radical scavenging activity and FRAP were of $700 \mu$ mole $/ \mathrm{mL}$ trolox equivalent and 340 $\mu$ mole $/ \mathrm{mL} \mathrm{Fe} 2+$ equivalent, respectively. It is interesting in this study to investigate health benefits of lady finger when regularly consumed as a vegetable.

Testing for cytotoxicity of the extract was priory performed by using MTT assay, and the cell viability of not less than $80 \%$ would be indicated as safe. Data corresponding to this cytotoxic test on L929 fibroblastic cells should be referred to those of our previous study (Manee and Kaewsrichan, 2017). Three different cell types, including $\mathrm{C} 2 \mathrm{C} 12$ muscle cells, PC12 adrenal cells, and RBM-MSCs bone stem cells that associated to this work were recently tested. Results showed that $\mathrm{C} 2 \mathrm{C} 12$ and $\mathrm{PC} 12$ cells could tolerate to a concentration range of $1.25-2.5 \mathrm{mg} / \mathrm{mL}$ extract, while the viability of RBMMSCs cells was observed at a lower concentration range of $0.5-1.25 \mathrm{mg} / \mathrm{mL}$ extract. In accordance, each maximal concentration level will be used for treating the respective cells in next experiments, i.e., $2.5 \mathrm{mg} / \mathrm{mL}$ for $\mathrm{C} 2 \mathrm{C} 12$ and $\mathrm{PC} 12$ cells, and $1.25 \mathrm{mg} / \mathrm{mL}$ for RBM-MSCs cells.

C2C12 cells were cultured in medium supplemented with 350 mmole/L glucose to mimic the main pathological condition of diabetes mellitus (Newsholme et al., 2007). Such hyperosmotic medium induced cell death by approximately 36.92 $\pm 0.90 \%$, as determined by TUNEL assay. After treating with the extract of $2.5 \mathrm{mg} / \mathrm{mL}$, the number of dead cells was significantly decreased to $24.55 \pm 0.48 \%$. Thus, those injured cells were possibly rescued by the extract, becoming healthy cells which can grow and proliferate. Commonly, diabetes patients may suffer from muscle weakness of the lower limbs, which increases the risk of falling (Woodfield, 2016). Therefore, sufficient consumption of lady finger may be a way for increasing healthy muscle cells, which leads to improved muscle mass and strength. However, deep investigation on mechanisms underlining such muscular effect is awaited to discover. In contrast to $\mathrm{C} 2 \mathrm{C} 12$ cells, the proliferative capacity of glucose-treated PC12 cells was not improved by such treatment. These cells seemed to be more vulnerable to glucose toxicity than the muscle cells described above. Regarding the physiology, adrenal cells function in synthesis and secretion of glucocorticoids, mineralocorticoids, and androgenic steroids, which are strictly controlled by corticotrophinreleasing hormone of hypothalamus and adrenocorticotrophic hormone of anterior pituitary gland, respectively. Cortisol is the major glucocorticoid in human. To our knowledge, alteration of circulating cortisol has dramatic effects on the body by increasing appetite, promoting triglyceride accumulation, 
and obesity (Lucassen and Cizza, 2012). Therefore, plant extracts capable in protection of adrenal cells death are requested to research.

Free radicals and reactive species, especially super oxide anion $\left(\mathrm{O}_{2}^{-}\right)$, are constantly generated by the normal body metabolisms through mitochondrial energy production pathway. Cellular oxidative stress may occur when the level of oxidant species exceeds that of antioxidants and be implicated in the incidence and progression of several health problems and chronic diseases (Giustarini et al., 2009). SOD, CAT, and glutathione peroxidase (GPX) act promptly against free radicals to protect vital macromolecules and body tissues (Ighodaro and Akinloye, 2018). Determination of SOD and CAT activities before and after treating with $2.5 \mathrm{mg} / \mathrm{mL}$ extract was consequently carried out. The SOD activity of $\mathrm{C} 2 \mathrm{C} 12$ cells cultured in $350 \mathrm{mmole} / \mathrm{L}$ glucose supplemented medium was 1.59-fold compared to the control, and was slightly increased to 1.80 -fold after treatment. For PC12 cells, the SOD activity in the present of such high glucose concentration was 11.34-fold compared to the control, but decreased to 2.24-fold by such challenge. Results indicated that the circumstance of high glucose was very toxic to PC12 cells compared to $\mathrm{C} 2 \mathrm{C} 12$ cells. It also seemed that $\mathrm{PC} 12$ cells were more sensitive to the extract treatment by increasing SOD production than $\mathrm{C} 2 \mathrm{C} 12$ cells. The CAT activity of $\mathrm{C} 2 \mathrm{C} 12$ cells cultured in glucose containing medium was accountable to be $23.79 \mathrm{mU} / \mathrm{mL}$ and was significantly decreased to 17.04 $\mathrm{mU} / \mathrm{mL}$ after treatment. For non-challenging, non-treating $\mathrm{C} 2 \mathrm{C} 12$ cells (control), the enzyme activity was $3.42 \mathrm{mU} / \mathrm{mL}$. In contrast, the CAT activity was not detected for PC12 cells. To limit the oxidative stress of high glucose, C2C12 cells were thus simply challenged by the extract for increased production of the CAT enzyme. Instead, PC12 cells trended to die when in contact with the non-favorable environment due to the scant of CAT activity.

L929 cells that made oxidative stress by culturing in medium containing $37.5 \mu \mathrm{mole} / \mathrm{L}$ DPPH for $30 \mathrm{~min}$ were investigated for proliferative activity after treatment with the extract for 2 days. Results showed that the distance closure of the scratched lines was improved by approximately 55\% and $84 \%$ on day 1 and day 2 of the treatment, respectively. In addition, the extract demonstrated inhibitory activity on the released TNF- $\alpha$ and IL- 6 by about $40.5 \%$ and $86.3 \%$, after 2 days of incubation. Therefore, the extract might help recovery of the injured cells to become healthier, which could begin proliferation and growth. Inhibition of TNF- $\alpha$ and IL- 6 activity by the extract might be suggested as a role for mending the distorted cells. There is an agreement in that prolonged inflammation and increased oxidative stress impair healing in diabetes (Kant et al., 2014). Focusing on beneficial effects by increasing SOD and CAT activity and decreasing TNF- $\alpha$ and IL-6 activity, the extract might be implicated for ameliorating damaged cells, tissues, and organs affected by diabetes.

Hyperglycaemic condition can induce skeletal muscle to be resistant to insulin, resulting in lowered glucose uptake (Shannon et al., 2018). Then, C2C12 cells were determined for glucose uptake ability in response to the elevated glucose concentration in culture medium and the present of the extract. 2-NBDG is a fluorescent glucose analogue, which is used for monitoring glucose uptake in live cells. In this study, the percentage (\%) of cells being fluorescent as $2-\mathrm{NBDG}$ was taken up was analysed by flow cytometry. Results showed that glucose uptake activity of $\mathrm{C} 2 \mathrm{C} 12$ cells was promoted following treated with the extract in compared to the untreated control. The acquired fluorescent signal was equivalent to those challenged by $200 \mathrm{nmole} / \mathrm{L}$ insulin. Consequently, the extract seemed to be advantageous for improving hyperglycemic condition by increasing glucose uptake and reducing glucose tolerance. Several mechanisms regarding glucose uptake amelioration have been reported, such as activation of Peroxisome Proliferator-Activated Receptors (PPARs) (Dubois et al., 2017), and upregulation of adiponectin receptor (Kim and Park, 2019). To this context, mechanisms underlining the improvement of glucose uptake by the extract in $\mathrm{C} 2 \mathrm{C} 12$ cells are being investigated.

High blood glucose concentrations can cause injury of a large number of tissues and organs. Although most cells can adapt the rate of glucose influx under hyperglycaemic condition to protect their intracellular milieu, some cells such as beta cells, neuronal cells, and endothelial cells, do not have such adaptive mechanism. These cells are thus more susceptible to oxidative stress caused by hyperglycaemia than others (Marcovecchio, 2017). RBM-MSCs were chosen for measuring intracellular oxidative stress in response to high glucose concentrations, because this cell type is of mesenchymal origin and responsible in forming muscle, and lymphatic and blood vessels, and would be used in estimating hyperglycaemic effect on endothelial cells (Bianco et al., 2008). DCFH$\mathrm{DA}$ is a nonpolar dye. Following taken up into cytoplasm, it is converted into DCFH by cellular esterase, which is nonfluorescent. DCFH is switched to highly fluorescent DCF when oxidized by intracellular ROS and other peroxides. Therefore, if intracellular ROS is generated, the images of green fluorescent cells will be obtained from a fluorescence microscope using 295, 320 or 395 nm cut-off filters (Rastogi et al., 2010). Results indicated that the green fluorescent intensity of the treated cells was lower than that of the untreated cells (Figure 1), suggesting that the extract presented antioxidant activity. 


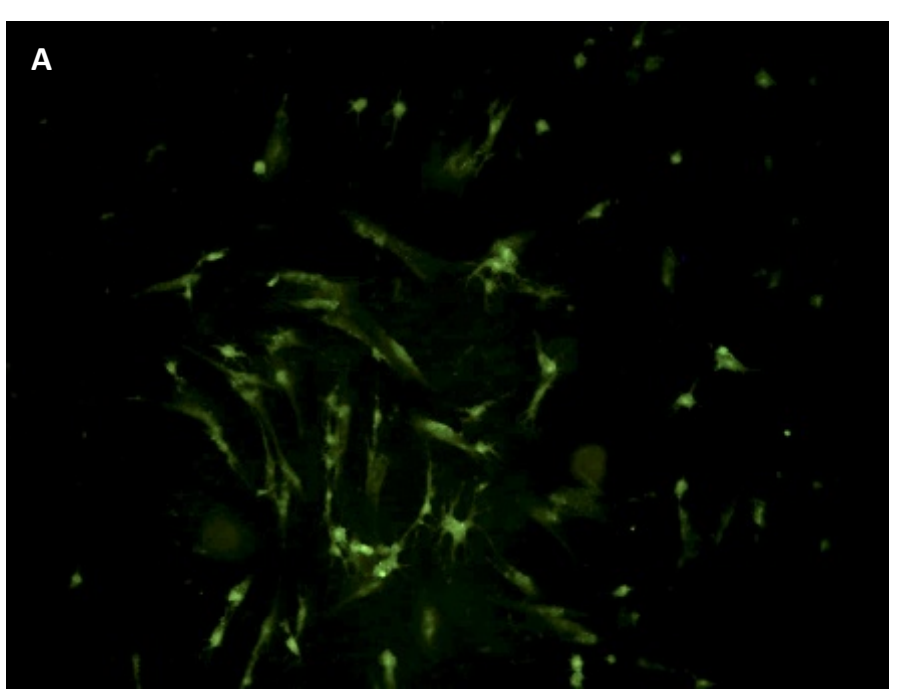

B

6

C

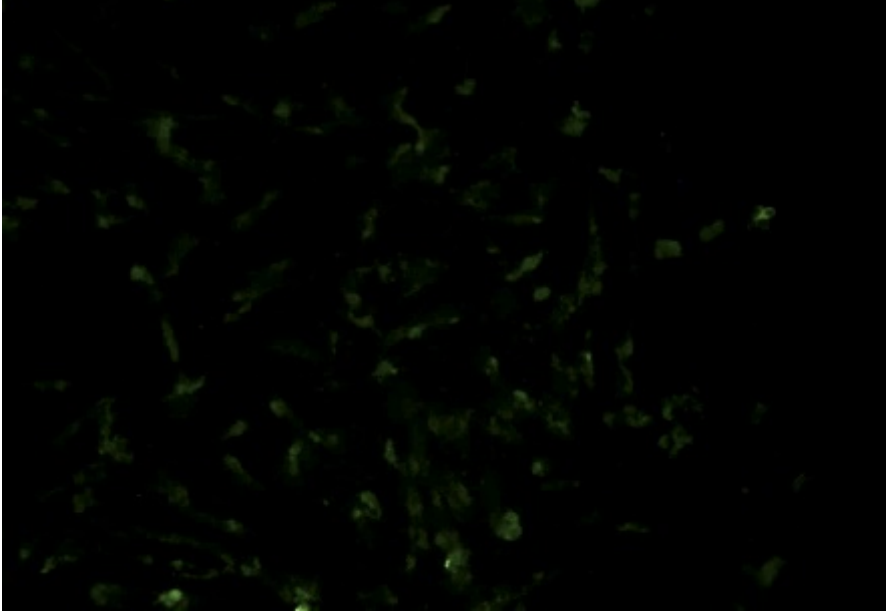

Figure 1.The fluorescence signal of DCFH-DA up taken by RBM-MSC cells. The cells were induced by $150 \mu$ mole/ $\mathrm{L} \mathrm{H}_{2} \mathrm{O}_{2}$ for $4 \mathrm{~h}$. a, control (without treatment); b, treated with $1.25 \mathrm{mg} / \mathrm{mL}$ extract; c, treated with $2.5 \mathrm{mg} / \mathrm{mL}$ extract 


\section{Conclusion}

It was concluded that the extract from seeds of lady finger displayed antioxidant and anti-inflammatory activities, as well as properties for fitting cells, promoting proliferation, and improving glucose uptake and insulin resistance. Thus, when regularly consumed as a vegetable, lady finger would be advantageous in management hyperglycaemia and diabetes.

Compliance with Ethical Standard

Conflict of interests: The authors declare that for this article they have no actual, potential or perceived the conflict of interests.

Funding: The financial support of this project was granted by Thailand national budget for the fiscal year 2018 under integrative research and innovative plan (Project No.: PHA610372S).

Ethics committee approval: No animals are used in this study

\section{References}

Alam, P., Parvez, M.K., Arbab, A.H., Siddiqui, N.A., AlDosary, M.S., Al-Rehaily, A.J., Ahmed, S., Kalam, M.A. Ahmad, M.S. (2017). Inter-species comparative antioxidant assay and HPTLC analysis of sakuranetin in the chloroform and ethanol extracts of aerial parts of Rhus retinorrhoea and Rhus tripartita. Pharmaceutical Biology, 55(1), 1450-1457. https://doi.org/10.1080/13880209.2017.1304428

Azlim Almey, A., Ahmed Jalal Khan, C., Syed Zahir, I., Mustapha Suleiman, K., Aisyah, M. Kamarul Rahim, K. (2010). Total phenolic content and primary antioxidant activity of methanolic and ethanolic extracts of aromatic plants' leaves. International Food Research Journal, 17(4), 10771084.

Bianco, P., Robey, P.G. Simmons, P.J. (2008). Mesenchymal stem cells: revisiting history, concepts, and assays. Cell stem Cell, 2(4), 313-319.

https://doi.org/10.1016/j.stem.2008.03.002

Castro, A., Macedo-de la Concha, L. Pantoja-Meléndez, C. (2017). Low-grade inflammation and its relation to obesity and chronic degenerative diseases. Revista Médica del Hospital General de México, 80(2), 101-105.

https://doi.org/10.1016/j.hgmx.2016.06.011
Dubois, V., Eeckhoute, J., Lefebvre, P. Staels, B. (2017). Distinct but complementary contributions of PPAR isotypes to energy homeostasis. The Journal of clinical investigation, 127(4), 1202-1214.

https://doi.org/10.1172/JCI88894

Giustarini, D., Dalle-Donne, I., Tsikas, D. Rossi, R. (2009). Oxidative stress and human diseases: origin, link, measurement, mechanisms, and biomarkers. Critical Reviews in Clinical Laboratory Sciences, 46(5-6), 241-281.

https://doi.org/10.3109/10408360903142326

Healthy diet. (2018, October 23). Retrieved from https://www.who.int/news-room/fact-sheets/detail/healthydiet (accessed 18.08.2019).

A healthy, balanced diet. (2016, October). Retrieved from https://www.nutrition.org.uk/healthyliving/healthydiet/healthybalanceddiet.html (accessed 18.08.2019).

Ighodaro, O. Akinloye, O. (2018). First line defence antioxidants-superoxide dismutase (SOD), catalase (CAT) and glutathione peroxidase (GPX): Their fundamental role in the entire antioxidant defence grid. Alexandria Journal of Medicine, 54(4), 287-293.

https://doi.org/10.1016/j.ajme.2017.09.001

Kant, V., Gopal, A., Pathak, N.N., Kumar, P., Tandan, S.K. Kumar, D. (2014). Antioxidant and anti-inflammatory potential of curcumin accelerated the cutaneous wound healing in streptozotocin-induced diabetic rats. International Immunopharmacology, 20(2), 322-330.

https://doi.org/10.1016/j.intimp.2014.03.009

Kim, Y. Park, C.W. (2019). Mechanisms of adiponectin action: Implication of adiponectin receptor agonism in diabetic Kidney disease. International Journal of Molecular Sciences, 20(7), 1782.

https://doi.org/10.3390/ijms20071782

Lucassen, E.A. Cizza, G. (2012). The hypothalamic-pituitary-adrenal axis, obesity, and chronic stress exposure: sleep and the HPA axis in obesity. Current Obesity Reports, 1(4), 208-215.

https://doi.org/10.1007/s13679-012-0028-5 
Manee, S. Kaewsrichan, J. (2017). Cosmeceutical benefit of Abelmoschus esculentus L. seed extract. Journal of Pharmaceutical Research International, 19(6), 1-11.

https://doi.org/10.9734/JPRI/2017/37587

Marcovecchio, M.L. (2017). Complications of acute and chronic hyperglycemia. US Endocrinology, 13, 1-17.

https://doi.org/10.17925/USE.2017.13.01.17

Newsholme, P., Haber, E.P., Hirabara, S.M., Rebelato, E.L.O., Procopio, J., Morgan, D., Oliveira-Emilio, H.C., Carpinelli, A.R. Curi, R. (2007). Diabetes associated cell stress and dysfunction: role of mitochondrial and non-mitochondrial ROS production and activity. The Journal of Physiology, 583(1), 9-24.

https://doi.org/10.1113/jphysiol.2007.135871

Rastogi, R.P., Singh, S.P., Häder, D.-P. Sinha, R.P. (2010). Detection of reactive oxygen species (ROS) by the oxidantsensing probe $2^{\prime}, 7^{\prime}$-dichlorodihydrofluorescein diacetate in the cyanobacterium Anabaena variabilis PCC 7937. Biochemical and Biophysical Research Communications, 397(3), 603-607.

https://doi.org/10.1016/j.bbrc.2010.06.006

Rehakova, Z., Koleckar, V., Jahodar, L., Opletal, L., Macakova, K., Cahlikova, L., Jun, D. Kuca, K. (2014). Evaluation of the antioxidant activity of several naturally oc curring coumarins and their synthesized analogues by "ferric reducing antioxidant power" assay. Journal of Enzyme Inhibition and Medicinal Chemistry, 29(1), 49-54.

https://doi.org/10.3109/14756366.2012.753589

Shannon, C., Merovci, A., Tripathy, D., Abdul-Ghani, M., Norton, L. Defronzo, R.A. (2018). Effects of hyperglycemia on skeletal muscle glucose metabolism in healthy subjects. Diabetes, 67(Supplement 1), 1920-P.

https://doi.org/10.2337/db18-1920-P

Ware, M. (2019). Benefits and uses of okra. Retrieved from https://www.medicalnewstoday.com/articles/311977.php

(accessed 15.11.2019)

Wongwitwichot, P., Kaewsrichan, J. (2017). Induction of rat marrow stromal cells by FGF2 and insulin activates transcription of runx2 gene through ap1 consensus sequence. Journal of Advances in Medicine and Medical Research, 24(7), 1-15.

https://doi.org/10.9734/JAMMR/2017/37534

Woodfield, J. (2016, March 03). Study uncovers extent of muscle weakness in people with type 2 diabetes. Retrieved from https://www.diabetes.co.uk/news/2016/mar/study-uncovers-extent-of-muscle-weakness-in-people-with-type-2diabetes-92465800.html (accessed 18.08.2019). 